\title{
РАЗВИТИЕ СЕВЕРНОГО МОРСКОГО ПУТИ: НАЦИОНАЛЬНЫЙ И МЕЖДУНАРОДНЫЙ АСПЕКТЫ
}

Аннотация. В статье раскрываются особенности Северного морского пути (СМП), анализируется его начиональный и международный аспект. Анализируются современные предложения и инновации по развитию Севморпути. СМП рассматривается как один из транзитных марирутов в рамках китайской инициативь «Один пояс, один путь», в частности, в форме «Ледяного Шёлкового пути».

Ключевые слова: Северный морской путь, Арктический совет, Арктика, Россия, «Ямал $С П Г »$.

В последнее время тема развития Северного морского пути (СМП) и освоения Арктики активно звучит как в России, так и во всём мире. Ведущие эксперты в России, Европе и Азиатско-Тихоокеанском регионе считают, что за ним будущее мировой морской логистики и торговли ${ }^{1}$. Ряд специалистов высказывают опасения, что существующие на Севморпути геополитические и естественные ограничения могут повлиять на его конкурентоспособность по сравнению с более предсказуемыми маршрутами ${ }^{2}$.

\section{Национальный аспект развития СМП}

Северный морской путь - это единственный судоходный маршрут, связывающий все арктические и субарктические регионы Российской Федерации. Вместе с многочисленными реками, впадающими в Северный Ледовитый океан, он представляет собой единую транспортную систему, соединяющую территории России по линии «Юг-Север».

Традиционно СМП связан с ключевыми промышленными кластерами страны: Норильским комбинатом, Восточно-Сибирским нефтегазовым комплексом, добывающими предприятиями Якутии, Магадана, Чукотки (добыча золота, цветных и редких металлов), лесоэкспортирующими предприятиями Архангельской области. Его развитие в перспективе будет напрямую увязано с освоением и транспортировкой минеральных и энергетических ресурсов Тимано-Печорской провинции, Обской губы, полуострова Ямал, шельфов Баренцева и Карского морей.

(c) Журавель Валерий Петрович - кандидат педагогических наук, ведущий научный сотрудник, руководитель Центра арктических исследований Отдела страновых исследований ИЕ РАН. Адрес: 125009, Россия, Москва, ул. Моховая, д. 11, стр. 3. E-mail: zhvalery@ mail.ru.

DOI: http://dx.doi.org/10.15211/vestnikieran22019119124

${ }^{1}$ Дмитриева С.И., Полянский М.А. Арктический регион в контексте интересов российской внешней политики. Журнал российского права, №3, 2017 г. С. 148-157; Сунь Сювэнь. Потенциал международного сотрудничества РФ и КНР в Арктике: сравнительный анализ национальных интересов. Социально-политические науки, №3, 2017 г. С. 12-17; Тодоров А.А. Международный транзитный потенциал Северного морского пути: экономический и правовой аспект. Проблемы национальной стратегии, №3, 2017 г. С. 149-171.

2 Ларченко Л.В., Колышкин А.В., Яковлева Т.В., Нелюбина Л.В. Может ли Северный морской путь стать конкурентоспособным международным транзитным путём. Инновации, №10, 2018 г. С. 64-67; Смаль С.В., Ильясов P.M. Северный морской путь: проблемы стратегического развития и перспективы международного использования. Общество: политика, экономика, право, №6, 2018 г. С. 14-16. 
Датой начала освоения СМП нужно считать 1932 г., когда он был пройден за одну навигацию советской экспедицией, возглавляемой О.Ю. Шмидтом на ледокольном пароходе «Александр Сибиряков». Рекорд перевозок в СССР по Севморпути был поставлен в 1987 г. 6,6 млн т. Этот показатель был превышен Россией только через 19 лет в 2016 г. и составил 7,3 млн т. В 2018 г. он достиг 20 млн т ${ }^{1}$.

Пристальное внимание к Севморпути началось после принятия в 2012 г. закона о СМП. С 2013 г. осуществлён целый комплекс мероприятий по его развитию, совершенствованию организационной структуры управления, обеспечению безопасности судоходства в Арктической зоне РФ (АЗРФ), реструктуризации и росту объёмов грузоперевозок. Было создано федеральное государственное казенное учреждение «Администрация Северного морского пути», утверждены «Правила плавания в акватории СМП». Его развитие увязано с инвестиционными проектами по строительству новых железных дорог - «Северный широтный ход» и «Белкомур», которые призваны содействовать экспорту через отечественные порты в акватории Северного Ледовитого океана продукции предприятий Северного Урала и Западной Сибири. В соответствии с Федеральным законом от 27.12.2018 № 525-Ф3 «О внесении изменений в отдельные законодательные акты Российской Федерации» Госкорпорация «Росатом» приняла функционал единого инфраструктурного оператора Северного морского пути.

Новый подход к функционированию Севморпути состоит в значительном увеличении объёмов его грузоперевозок с параллельным развитием российских арктических территорий в рамках опорных зон развития. В указе Президента РФ от 7 мая 2018 г. № 204 «О национальных целях и стратегических задачах развития Российской Федерации на период до 2024 года» поставлена задача довести грузопоток по СМП к 2024 г. до 80 млн тонн.

В конце декабря 2018 г. Правительство РФ определило меры по дальнейшему комплексному развитию СМП. С марта 2019 г. началась выполнение принятых решений. Приняты меры по дальнейшему совершенствованию навигационно-гид-рографического обеспечения и безопасности судоходства на трассах Севморпути. Разрабаты-ваются и внедряются метео-, гидро- и ледовые сервисы, перспективные направления радиосвязи для проведения аварийно-спасательных работ, беспилотные летательные аппараты для мониторинга и ледовой разведки.Президент России В.В. Путин подписал указ № 78 от 26 февраля 2019 г. о передаче Минвостокразвития РФ функций по выработке и реализации государственной политики и нормативно-правовому регулированию в сфере социально-экономического развития Арктики, а также переименовании его в Министерство Российской Федерации по развитию Дальнего Востока и Арктики.

В связи с активизацией в Арктической зоне военно-морской деятельности различных государств Правительство РФ разработало правила прохода иностранных военных кораблей по СМП. Военные корабли и суда других стран должны будут уведомить российскую сторону за 45 суток до прохода по Севморпути. При этом требуется сообщать название корабля, маршрут и сроки плавания, основные параметры плавсредства (водоизмещение, осадка, характеристики двигателя), а также указывать воинское звание и фамилию капитана. Иностранные корабли и суда будут обязаны брать на борт российских лоцманов. В случае возникновения аварийной ситуации или осложнения ледовой обстановки российские ледоколы окажут им помощь ${ }^{3}$.

\footnotetext{
1 Эту цифру президент РФ В.В. Путин назвал в своём выступлении на V Международном форуме «Арктикатерритория диалога» 9 апреля 2019 г.

O решениях по итогам совещания по вопросам развития Арктики. URL: http://govern ment.ru/orders/selection/401/35123/ (дата обращения: 21 декабря 2018 г.).

${ }^{3}$ В России созданы правила прохода Севморпути иностранными кораблями. 06.03.2019 г. URL: http://www.a Научно-аналитический вестник ИЕ РАН, 2019, №2
} 
Принимаются меры по дальнейшему развитию современного ледокольного флота. В настоящее время в акватории Севморпути действуют восемь линейных ледоколов: четыре атомных ${ }^{1}$ и столько же дизель-электрических, что для обеспечения судоходства по СМП недостаточно.

По мнению экспертов, до 2030 г. для обеспечения надёжной и своевременной навигации по Северному морскому пути нужно построить до десяти новых атомных ледоколов. На дальневосточном заводе «Звезда» намечено строительство нового сверхмощного ато-мохода «Лидер», который должен стать единственным ледоколом в мире для круглогодичной проводки судов по СМП при толщине льда свыше 4 м. Он будет обладать повышенной мощностью и увеличенной шириной корпуса. Кроме этого, здесь идёт строительство судов для «Роснефти», «Газпрома», «Росморпорта», «Совкомфлота», а также для компании «НОВАТЭК».

Атомные ледоколы, суда ледового класса смогут выполнять в Арктике операции любой сложности, включая проводку судов, геологоразведку арктического дна, обеспечение нефтеи газодобычи, значительно усилят транспортную инфраструктуру СМП.

\section{Международный аспект развития СМП}

Северный морской путь - это кратчайший морской путь между портами Европы и Азии. Расстояние из голландского порта Роттердам до японского порта Йокогама (это Южный морской путь, идущий через Суэцкий канал) составляет 11205 морских миль, а при использовании СМП 7345 морских миль. СМП сокращает путь из Роттердама до порта Шанхая - на 2 449 морских миль, а до порта Ванкувера - на 1932 морских миль ${ }^{4}$. В среднем для перехода из Европы в Китай по Севморпути нужно 25 дней и 625 т мазута, а при использовании Суэцкого канала -35 дней и 875 т мазута ${ }^{5}$. Ледокольная проводка в календарном году нужна в период с ноября по июнь. В этих условиях наряду с российскими ледоколами возможно использование и иностранных судов.

Пока что Северный морской путь скромно представлен на карте международных морских перевозок. Он уступает потокам через Малаккский пролив, Суэцкий и Панамский каналы. Но при дальнейшем совместном с Китаем, Францией, Республикой Корея развитии проектов «Ямал СПГ» и «Арктик СПГ-2» роль СМП существенно возрастёт.

Превращение Севморпути в маршрут мирового масштаба в первую очередь зависит от глобального потепления, которое позволит осуществлять навигацию в арктических водах более длительный период. Одновре́менно уменьшение ледового покрова в Арктике может привести к тому, что традиционные трассы СМП, сейчас проходящие по внутренним морским водам, территориальному морю и исключительной экономической зоне Российской Федерации, станут более высокоширотными. В этом случае часть трассы Севморпути будет находиться за пределами зон суверенитета и юрисдикции России, которая в таком случае уже не будет обладать правовыми полномочиями по контролю над североморским судоходством. Трасса

retic info.ru/news/bezopasnost/V_Rossii_sozdany_pravila_prokhoda_Sevmorputi_inostrannymi_korablyami (дата обращения: 15 марта 2019 г.).

1 У ледоколов «Ямал», «50 лет Победы», «Таймыр» и «Вайгач» срок эксплуатации

${ }_{3}^{2}$ URL: (дата обращения: 15 декабря 2018 г.).

3 Воробьев В.М. Создание ледокола-лидера - важнейший этап в коммерческом развитии регионов Арктики. Арктические ведомости, №1, 2017 г. С. 160-163.

4 Ларченко Л.В., Колышкин А.В., Яковлева Т.В., Нелюбина Л.В. Может ли Северный морской путь стать конкурентоспособным международным транзитным путём. Инновации, №10, 2018 г. С. 64.

5 Редкие земли. Возрождение Северного морского пути - главная забота российских полярников. 01.07.2016. URL: http://rareearth.ru/ru/pub/20160601/02203.html) дата обращения: 21 декабря 2018 г.).

Научно-аналитический вестник ИЕ РАН, 2019, №2 
СМП из категории национальной транспортной артерии, находящейся под российским контролем, может превратиться в международный судоходный маршрут. Перестанет существовать необходимость обязательного обеспечения ледокольной и лоцманской проводкой со стороны России, регулирование судоходства будет осуществляться Международной морской организацией и регулироваться соответствующими международными конвенциями. Такой сценарий, конечно же, пока маловероятен, так как изменения климата, вероятнее всего, носят циклический характер. Но его надо учитывать при планировании политики РФ в Арктике.

Особое значение будет иметь стоимость нефти ${ }^{1}$. При сохранении в течение длительного времени низкой цены СМП будет труднее конкурировать с таким гигантом, как Суэцкий канал, где плата за проход на треть ниже, чем за ледокольное сопровождение судов.

Ряд объективных негативных факторов существенно снижают преимущества Севморпути. К ним относится короткий навигационный период для плавания без сопровождения ледоколом; тяжёлые погодные условия и движение льдов; угрозы ледового сжатия и повреждения судов из-за сложной ледовой обстановки, что может привести к простою и дополнительным страховым расходам, а также большой износ основных фондов портового хозяйства. Из 71 порта на трассе Северного морского пути 66 имеют загрузку менее 100 тыс. т или не функционируют вовсе. Причалы большинства арктических портов требуют капитального ремонта и углубления дна для приёма современных судов ${ }^{2}$.

Эти проблемы сегодня решаются за счёт безошибочной проводки специальных судов высокого ледового класса, профессионального уровня действий экипажей в арктических условиях. Важный вклад вносят дальнейшее совершенствование таможенного и пограничного контроля, повышение качества сервисных услуг, создание современных каналов связи для постоянного отслеживания движения грузов, а также работы по дальнейшей модернизации портовой инфраструктуры портов и строительству новых терминалов.

Россия из-за нехватки финансов и необходимых технологий, к сожалению, не может самостоятельно и в полном объёме реализовывать крупные проекты типа «Ямал СПГ» и «Арктик СПГ-2». Проблема обострилась после введения экономических санкций со стороны западных стран. В этом контексте необходимо продолжение долгосрочного сотрудничества с азиатскими странами - Китаем, Японией, Республикой Корея и Сингапуром. Японская компания «Mitsui O.S.K. Lines» и китайская компания «China COSCO Shipping» участвуют в разработке и эксплуатации морского порта Сабетта. Корейская компания «Hyundai Merchant Marine Co» совместно с китайской «Poly Group» рассматривают возможность участия в проекте по реконструкции Архангельского глубоководного морского порта и разработке Мурманской транспортной системы. Корейская судоходная компания «Нyundai Merchant» планирует протестировать транзитные перевозки контейнерных судов мощностью 2500-3500 $\mathrm{TEU}^{3}$ вдоль СМП в 2020 г. Кроме того, эти страны смогут начать поставки с помощью международных караванов грузовых судов, для которых Россия может снизить сборы.

СМП рассматривается как один из транзитных маршрутов в рамках китайской инициативы «Один пояс, один путь», в частности, в форме «Ледяного Шёлкового пути». Последний может стать частью программы взаимной стыковки проектов России и Китая, в том числе в рамках строительства инфраструктуры по линиям «Юг-Север» для обеспечения освоения

\footnotetext{
${ }^{1}$ Мастепанов А.М. Нефтегазовые проекты на Арктическом шельфе в условиях высоких и низких цен на энергоресурсы. Научный журнал Российского газового общества, №4, 2016 г. С. 11-18.

Козлова А. Мы пойдём Северным морским путём. Сможет ли маршрут по российской Арктике заменить южную транспортную артерию через Суэцкий канал? Комсомольская правда, 02.04.2019 г.

${ }^{3}$ Единица эквивалентная двадцати футам.
} 
прибрежного арктического пространства, в частности, и через дороги, ведущие к российским арктическим по́ртам со стороны стран Центральной Азии. В этих условиях важно более активно подключать к решению проблем Арктики страны ЕАЭС, например, в сфере использования передовых наработок в области создания машин и агрегатов для работы в сложных климатических условиях, а также привлечения инженерных кадров в строительство и совершенствование арктической инфраструктуры.

Для интеграции Севморпути в мировую транзитную систему в качестве эффективного евроазиатского транспортного коридора при условии сохранения своего суверенитета в Арктике России необходимо совершенствовать его инфраструктуру, создавать условия для развития контейнерных перевозок, привлекать крупнейших международных судовладельцев и грузовладельцев для перевозки грузов.

\section{Выводы}

Развитие СМП является необходимым условием обеспечения геополитической и военной безопасности РФ, надёжных транспортных связей и увеличения грузопотока, нормальных условий жизнедеятельности на северных территориях, ускоренного освоения месторождений полезных ископаемых, экспорта нефти и газа.

Комплексное рассмотрение Правительством РФ состояния и перспектив развития СМП нацелено на разрешение накопившихся проблем и ускоренное социально-экономическое развитие АЗРФ. Есть понимание того, что Арктический регион является важнейшей частью территории России. На наш взгляд, развитие Севморпути необходимо сделать отдельным национальным проектом.

В настоящее время функционирование СМП направлено на обустройство и развитие арктических регионов России, добычу, переработку полезных ископаемых и отправку их на экспорт. Строительство «Ледового Шёлкового пути», активное привлечение к арктическим вопросам ЕАЭС будет способствовать построению мощной транспортной инфраструктуры по суше и морю между Азией и Европой. Строительство «Ледового Шёлкового пути» вдоль северных берегов России поможет экономическому развитию. В будущем СМП должен составлять основу Арктической транспортной системы, в которую должен входить комплекс транспортных средств морского и речного флота, авиации, трубопроводного, железнодорожного и автомобильного транспорта, а также береговой инфраструктуры.

\section{Список литературы}

Альтернативный маршрут. За CMП будущее мировой морской логистики и торговли. URL: http://www.eastrussia.ru/material/alternativnyy-marshrut/ дата обращения: 21.12.2018).

Воробьев В.М. Создание ледокола-лидера - важнейший этап в коммерческом развитии регионов Арктики. Арктические ведомости, №1, 2017 г. С. 160-163.

В России созданы правила прохода Севморпути иностранными кораблями. 06.03.2019 г. URL: http://www.arcticinfo.ru/news/bezopasnost/V_Rossii_sozdany_pravila_prokhoda_Sevmorpu ti_inostrannymi_korablyami (дата обращения: 15.03.2019).

Козлова А. Мы пойдём Северным морским путём. Сможет ли маршрут по российской Арктике заменить южную транспортную артерию через Суэцкий канал? Комсомольская правда, 02.04.2019 г.

Ларченко Л.В., Колышкин А.В., Яковлева Т.В., Нелюбина Л.В. Может ли Северный морской путь стать конкурентоспособным международным транзитным путём. Инновации, №10, 2018 г. С. 64-67.

Мастепанов А.М. Нефтегазовые проекты на Арктическом шельфе в условиях высоких и низких цен на энергоресурсы. Научный журнал Российского газового общества, №4, 2016 г. С. 11-18.

URL: (дата обращения: 15.12.2018).

URL: http://government.ru/orders/selection/401/35123/(дата обращения: 21.12.2018). 
Редкие земли. Возрождение Северного морского пути - главная забота российских поляр-ников. 01.07.2016 г. URL: http://rareearth.ru/ru/pub/20160601/02203.html дата обращения: 21.12.2018).

Смаль С.В., Ильясов Р.М. Северный морской путь: проблемы стратегического развития и перспективы международного использования. Общество: политика, экономика, право, №6, 2018 г. С. 1416.

Указ Президента РФ от 7 мая 2018 г. № 204 «О национальных целях и стратегических задачах развития Российской Федерации на период до 2024 года». URL: http://www.kremlin.ru/ events/president/news/57425 (дата обращения: 11.05.2018).

\section{References}

Alternativnyj marshrut. Za SMP budushchee mirovoj morskoj logistiki i torgovli. URL: http:// www.eastrussia.ru/material/alternativnyy-marshrut/ data obrashcheniya: 21.12.2018).

Vorob'ev V.M. Sozdanie ledokola-lidera - vazhnejshij ehtap v kommercheskom razvitii region-nov Arktiki. Arkticheskie vedomosti, №1, 2017 g. C. 160-163.

V Rossii sozdany pravila prokhoda Sevmorputi inostrannymi korablyami. 06.03.2019 g. URL: http://www.arctic info.ru/news/bezopasnost/V_Rossii_sozdany_pravila_prokhoda_Sevmorputi_ino strannymi_korablyami (data obrashcheniya: 15.03.2019).

Kryukov V.A. Sever i Arktika. Bez svyazannosti net ustojchivosti. EKO: vserossijskij ehkonomicheskij zhurnal, №4, 2018 g. S. 4-7.

Larchenko L.V., Kolyshkin A.V., YAkovleva T.V., Nelyubina L.V. Mozhet li Severnyj morskoj put' stat' konkurentosposobnym mezhdunarodnym tranzitnym putyom. Innovacii, №10, 2018 g. S. 64-67.

Mastepanov A.M. Neftegazovye proekty na Arkticheskom shelfe v usloviyah vysokih i nizkih tsen na ehnergoresursy. Nauchnyj zhurnal Rossijskogo gazovogo obshchestva, №4, 2016 g. C. 11-18.

Redkie zemli. Vozrozhdenie Severnogo morskogo puti - glavnaya zabota rossijskih polyarnikov. 01.07.2016 g. URL: http://rareearth.ru/ru/pub/20160601/02203.html (data obrashcheniya: 21.12.2018 g.).

Smal S.V., Il'yasov R.M. Severnyj morskoj put: problemy strategicheskogo razvitiya i perspektivy mezhdunarodnogo ispolzovaniya. Obshchestvo: politika, ehkonomika, parvo, №6, 2018 g. S. 14-16.

Ukaz Prezidenta RF ot 7 maya 2018 g. № 204 «O nacional'nyh celyah i strategicheskih zadachah razvitiya Rossijskoj Federacii na period do 2024 goda». URL: http://www.kremlin.ru/ events/president/news/57425 (data obrashcheniya: 11.05.2018 g.).

\section{Development of the Northern sea route: national and international aspects}

Author. Valery Zhuravel, Candidate of Sciences (Pedagogics), Leading Research Associate, Head of the Centre for Arctic Studies, Institute of Europe, Russian Academy of Sciences. Address: 11-3, Mokhovaya str., Moscow, Russia, 125009. E-mail: zhvalery@mail.ru.

Abstract: The paper reveals the features of the Northern Sea Route (NSR), analyzes its national and international aspects. Relevant proposals and innovations for the development of the Northern Sea Route are analyzed. The NSR is considered as one of the transit routes in the framework of the Chinese initiative «One Belt, One Road», in particular, in the form of the «Polar Silk Road».

Key words: Northern Sea Route, Arctic Council, Arctic, Russia, Yamal LNG.

DOI: http://dx.doi.org/10.15211/vestnikieran22019119124 